\title{
Jabbaren, Ijabbaren, Ijobbaren et Isabaten
}

\section{H. Claudot-Hawad}

\section{OpenEdition}

Journals

Édition électronique

URL : http://journals.openedition.org/encyclopedieberbere/1466

DOI : 10.4000/encyclopedieberbere. 1466

ISSN : 2262-7197

\section{Éditeur}

Peeters Publishers

\section{Édition imprimée}

Date de publication : 1 septembre 2003

Pagination : 3842-3844

ISBN : 2-7449-0424-4

ISSN : 1015-7344

\section{Référence électronique}

H. Claudot-Hawad, « Jabbaren, ljabbaren, ljobbaren et Isabaten », Encyclopédie berbère [En ligne], 25 | 2003, document J01b, mis en ligne le 01 juin 2011, consulté le 25 septembre 2020. URL : http:// journals.openedition.org/encyclopedieberbere/1466; DOI : https://doi.org/10.4000/ encyclopedieberbere.1466

Ce document a été généré automatiquement le 25 septembre 2020.

(c) Tous droits réservés 


\title{
Jabbaren, Ijabbaren, Ijobbaren et Isabaten
}

\author{
H. Claudot-Hawad
}

\section{NOTE DE L'AUTEUR}

[La célèbre station rupestre de Jabbaren doit son nom au mot touareg (dans la variante tamâhaq : sing. ajabbar, plur. ijabbaren)qui désigne une population ancienne de géants.]

Dans l'histoire légendaire touarègue, les Ijabbaren, Ijobbaren ou Isabaten selon les régions, ou encore les Ixazamen considérés comme antérieurs, apparaissent soit comme les premiers ancêtres des Touaregs avant que leur société n'émerge en tant que telle, soit comme le peuple qui les a précédés. Dans ce schéma, les Ijobbaren apparaissent comme les autochtones, apparentés ou non aux nouveaux arrivants que seraient les ancêtres fondateurs directs des Touaregs (Imajayen, Imuhay, Imušay, Kel Tamašaq, selon les parlers), toujours présentés comme issus d'un ailleurs prestigieux, grand pôle de commerce ou de culture, qui varie selon la période historique considérée.

2 Pour décrire ce peuple des origines, intervient un motif légendaire, partagé avec d'autres régions berbérophones et plus largement nord-africaines : leur gigantisme. Ainsi, laissant des traces à leur mesure, les Ijobbaren seraient les auteurs des vestiges préhistoriques monumentaux, tels que les imposantes tombes circulaires à tumulus certaines datées du $\mathrm{VIII}^{\mathrm{e}}$ ou $\mathrm{VII}^{\mathrm{e}}$ millénaires avant J.-C. et attribuées par les préhistoriens aux proto-berbères (Hachid, 2000) -, les immenses gravures rupestres ou encore, plus tardives, les inscriptions libyques qui s'apparentent aux tifinay, mais ne sont pas décodables [voir notice « Écriture »].

3 D'un point de vue touareg, cette écriture antique est jugée maladroite, le tracé des signes et leur sens de lecture présentés comme anarchiques et les mots demeurent indéchiffrables. En fait, ces hommes d'autrefois, dont on reconnaît la force et la productivité phénoménales, ont en même temps la réputation d'être frustres, grossiers, naïfs et plutôt pacifiques, ce qui n'est pas une qualité avantageuse dans une société qui 
valorise la guerre d'honneur. On prête à ces géants forts et doux des penchants idolâtres, faiblesse sympathique dont on se gausse sous les tentes à l'heure où se racontent les mythes d'origine. En ces temps anciens, d'ailleurs, la pierre est « molle ", image symbolique qui illustre la plasticité des matériaux qui servent à élaborer la culture et le manque d'assise de cette société à peine éclose, encore balbutiante.

4 Ainsi le portrait de ce peuple des origines est campé en opposition à celui, valorisé, des ancêtres fondateurs de la société et de la culture touarègues et s'attache à des traits significatifs des recompositions politiques et identitaires de la société contemporaine : l'opposition hiérarchisée entre nature et culture, ou entre barbarie et civilisation, se traduit ici par les distinctions établies entre origine locale obscure et origine extérieure prestigieuse, dialecte grossier et langue, abri naturel et tente, païen et musulman, petit bétail et chameaux, cueilleurs et éleveurs...

5 Par exemple, l'ancêtre légendaire des Kel Ahaggar, Ti-n-Hinan, selon une version recueillie par Foucauld au début $\mathrm{du} \mathrm{xx}^{\mathrm{e}}$ siècle, serait arrivée du Tafilalet (grand carrefour commercial au XIX siècle) sur son chameau blanc, en compagnie de sa servante, et n'aurait pas eu besoin d'armes pour dominer les derniers survivants des Isabaten : « courts d'esprit, ils parlaient la langue touarègue, mais en un dialecte spécial et grossier... Ils vivaient dans (des) cavernes. Ils voyaient de loin la grande plaine blanche de l'Aganar, la regardaient comme une divinité et la redoutaient» (1951, II : 536).

6 Selon un motif légitimant l'ordre social présent, certains groupements tributaires de l'Ahaggar sont considérés comme les descendants des Isabaten : « Les Isebeten, peuple idolâtre de langue touarègue qui habitait l'Ahaggar avant que l'islam s'y établit sont les ancêtres des plus anciennes tribus plébéiennes de l'Ahaggar tandis que les nobles sont venus d'une autre contrée à une époque postérieure et ont une origine différente " (Foucauld, 1951, II : 537)

7 La description mythique des Ijobbaren ou Isabaten a été rapprochée (voir H. ClaudotHawad, Annuaire de l'Afrique du Nord, 1999, Compte-rendu de la thèse de P. Bonté, L'émirat de l'Adrar. Histoire et anthropologie d'une société tribale du Sahara occidental, EHESS, Paris, 1998) du portrait des Bavur dans les traditions maures qui les associent aux sources, aux lieux défensifs où l'on trouve des restes d'habitat de pierre, aux tombes mégalithiques et aux palmeraies sauvages.

8 Ces récits de l'histoire orale, plutôt que de constituer les indices réalistes d'un peuplement du Sahara par vagues successives, les derniers arrivés dominant les populations existantes - construction légendaire unanimement reprise par les historiens, semblent d'abord exprimer, sur un mode plus symbolique, les recompositions sociales et politiques de la société autour de flux de biens matériels ou immatériels, de fonctions ou de valeurs d'un nouveau type. 


\section{BIBLIOGRAPHIE}

CAMPS G., Les Berbères aux marges de l'histoire, 1980.

CAMPS G, « L'âge du tombeau de Tin Hinan, ancêtre des Touaregs du Hoggar », Zephyrus 25, 1974, pp. 497-516.

CHAKER S., CLAUDOT H., GAST, M. (éds), Textes touaregs en prose de C. de Foucauld et A. de Motylinski, Édisud, Aix-en-Provence, 1985, Texte n 130 : « Les Isabaten », pp. 233-34.

Claudot-HAWAD H., Les Touaregs. Portrait en fragments, Aix-en-Provence, Édisud, 1995.

FOUCAULD CH. de, Dict. abrégé touareg-français de Noms propres, Paris, Larose, 1940.

FOUCAULD CH. de, Dictionnaire Touareg-Français, Dialecte de l'Ahaggar, Paris, Imprimerie nationale, 1950-1951, 4 vol.

HACHID M., Les Premiers Berbères, Aix-en-Provence/Alger, Édisud/Ina-Yas, 2000.

NORRIS H. T., The Berbers in Arabic Literature. London/N.Y, Longman, 1982.

INDEX

Mots-clés : Géants, Légende, Origines 